\title{
Naturopathy Education, Social Cognitive Theory, and the Precede-Proceed Model
}

\author{
Lisa Marie Portugal* \\ American College of Education, USA \\ Received: January 17, 2018; Published: January 24, 2018 \\ *Corresponding author: Lisa Marie Portugal, American College of Education, IN, USA, Email: lisamarieportugal@msn.com
}

\begin{abstract}
Social Cognitive Theory can address appropriate health and wellness change initiatives via the education of groups. Individualized and group action plans can be created and developed to address the overall health and wellness needs of families. This model and theory can assist in the education of preventing disease through health promotion and education and from a naturopathy perspective [1,2]. In addition, this model can assist in the development of health educational programs to understand and explain health behaviors and choices families make. The model can guide useful strategies and educational tools with in-person or online instructional modules.
\end{abstract}

\section{Introduction}

Social Cognitive Theory constructs can be applied to health behaviors by addressing health needs of families and parents in any group and in any region or country. The instructional tools can be created in any language once the basics of the curriculum have been written. The program can be taught in person via workshops, in clinics, or can be accessed online globally. The curriculum can be taught individually or in groups as well. Individualized learning styles, culture, and environment on the target population can be addressed using adult learning theories, scaffolding instructional techniques, differentiated instructional strategies, and technology integration to meet the needs of parents and families where they are at cognitively. These methods can assist in raising parent's and family's awareness in an interactive, intuitive manner regarding health and wellness education [3].

A holistic, qualitative approach can be used to address specific needs, ailments, health challenges, cultural background, and ability levels of groups and families. In addition, cognitive dissonance theory must be taken into account when developing this type of health and wellness program to address misinformation the public has been indoctrinated with over many years. The key is to address families and parents with a holistic, individualized, naturopathy perspective over a Big Pharma, prescription-driven, one-size-fitsall system emblematic of allopathic practitioners [3,4]. The goal is to self-empower, educate, change negative habits, and assist in the development of lifelong healthy habits. Furthermore, the plan can address the value of whole body healing from a naturopathy medicinal perspective. A compare and contrast of allopathic versus naturopathic practices can be examined and built into the curriculum.

\section{Social Cognitive Theory Mapping Template}

This example involves a group of parents. The parents have children of all ages and they tend to take family members to allopathic doctors mainly when someone is sick for vaccines, pharmaceutical drugs, antibiotics, and surgery. The goal is to educate parents and family members about

i. preventative healthcare / self-care in the home,

ii. natural remedies found in nature,

iii. natural nonGMO, Paleolithic diet or Paleo diet, and

iv. Using naturopathy doctors, providers, and services rather than allopathic and pharmaceutical services for healthcare needs (Table 1).

This plan addresses the existing health behaviors to help parents and families make a behavioral change by

i. educating them with appropriate tools according to their needs,

ii. informing them with current news

iii. supporting them with multiple resources, services, providers, and alternatives,

iv. providing support group access, and

v. providing follow-up, check-in or touch-base services, and on-going educational tools

This Social Cognitive Theory Mapping template is merely the vision or mapping out of overall goals and objectives. The specifics 
and details are created in a health and wellness educational plan and change initiative. Within a health and wellness educational plan, theories, principals, goals, objectives, strategies, techniques, instructional modules, workshops, services, providers, and program development tools are explained in further detail and depth.

Table 1.

\begin{tabular}{|c|c|c|c|}
\hline Construct & Definition & Scenario & Health Educator's Next Action \\
\hline $\begin{array}{c}\text { Reciprocal } \\
\text { Determinism }\end{array}$ & $\begin{array}{l}\text { People Influence <--> } \\
\text { Environment Influence }\end{array}$ & $\begin{array}{l}\text { Parent's surroundings are dominated by a busy } \\
\text { schedule not allowing them time to do research on } \\
\text { allopathic versus naturopathic medicine, natural } \\
\text { healthcare remedies versus pharmaceutical drugs, } \\
\text { vaccines, surgery and the damaging affects of } \\
\text { allopathic treatments. (Environment influencing } \\
\text { the parent's health behaviors) The parents } \\
\text { can have the desire and ability to change their } \\
\text { environment to increase their knowledge and } \\
\text { awareness in these areas. (People influencing the } \\
\text { environment for a change in health behavior). }\end{array}$ & $\begin{array}{l}\text { Present to parents how they can change their } \\
\text { environment to allow participation in healthcare } \\
\text { education, awareness, and trustworthy news. }\end{array}$ \\
\hline $\begin{array}{l}\text { Outcome } \\
\text { Expectancy }\end{array}$ & $\begin{array}{l}\text { Beliefs about the } \\
\text { likelihood and value of } \\
\text { the consequences of } \\
\text { behavioral choices }\end{array}$ & $\begin{array}{l}\text { Address parent's belief in their desire and ability } \\
\text { to make changes to environment to enhance } \\
\text { healthcare education, raising awareness, and } \\
\text { trustworthy news. }\end{array}$ & $\begin{array}{c}\text { Examine if the parents believe it might be possible } \\
\text { to make changes in their environment to educate } \\
\text { themselves about healthcare best practices and } \\
\text { trustworthy news. Assess whether parents might } \\
\text { value health consequences associated with making } \\
\text { behavioral changes. }\end{array}$ \\
\hline Self-Efficacy & $\begin{array}{l}\text { Beliefs about the ability } \\
\text { to perform behaviors that } \\
\text { bring desired outcomes }\end{array}$ & Parents perceive they can make change happen. & $\begin{array}{l}\text { Examine whether parents are assertive about } \\
\text { making changes in schedules to engage in } \\
\text { healthcare education, raising their awareness, and } \\
\text { learning where to find trustworthy news. }\end{array}$ \\
\hline $\begin{array}{l}\text { Collective } \\
\text { Efficacy }\end{array}$ & $\begin{array}{l}\text { Beliefs about the ability } \\
\text { of a group to perform } \\
\text { concerted actions that } \\
\text { bring desired outcomes }\end{array}$ & $\begin{array}{l}\text { Parents in the group, neighborhoods, area, schools, } \\
\text { churches, communities, etc. can form the social } \\
\text { network. In addition, social networks can also be } \\
\text { formed via the Internet, social media sites, and } \\
\text { websites to connect globally as well. }\end{array}$ & $\begin{array}{c}\text { Investigate parent's social network and determine } \\
\text { who might be supportive of new behavioral } \\
\text { changes. Buddy systems can be beneficial to } \\
\text { assist in holding groups of parents and families } \\
\text { accountable to each other. In addition, new } \\
\text { learning and sharing can assist in behavioral } \\
\text { changes as well. }\end{array}$ \\
\hline $\begin{array}{l}\text { Observational } \\
\text { Learning }\end{array}$ & $\begin{array}{l}\text { Learning to perform new } \\
\text { behaviors by exposure } \\
\text { to interpersonal, or } \\
\text { media displays of them, } \\
\text { particularly through peer } \\
\text { modeling }\end{array}$ & $\begin{array}{c}\text { Parents can learn how to make achievable } \\
\text { targets, establish sensible outcomes, and promote } \\
\text { techniques to defeat a lack of healthcare education, } \\
\text { awareness, and barriers in accessing trustworthy } \\
\text { news. }\end{array}$ & $\begin{array}{l}\text { Design in-person and online workshops, } \\
\text { instructional modules to assist parents in } \\
\text { the development of realistic goals, decide on } \\
\text { achievable outcomes, and tailor techniques to } \\
\text { overcome lack of healthcare education, awareness, } \\
\text { and barriers in accessing trustworthy news. }\end{array}$ \\
\hline $\begin{array}{l}\text { Incentive } \\
\text { Motivation }\end{array}$ & $\begin{array}{l}\text { The use and misuse of } \\
\text { rewards and punishments } \\
\text { to modify behavior }\end{array}$ & $\begin{array}{l}\text { Assess how to motivate parents to engage with } \\
\text { self-educational activities. Assess what might } \\
\text { be barriers to motivation, engagement, and } \\
\text { participation in self-educational activities. }\end{array}$ & Distinguish motivating and de-motivating elements \\
\hline Facilitation & $\begin{array}{l}\text { Providing tools, resources, } \\
\text { or environmental changes } \\
\text { that make new behaviors } \\
\text { easier to perform }\end{array}$ & $\begin{array}{l}\text { Some brief examples might include: journaling, } \\
\text { scheduling, calendar to plan week to engage in } \\
\text { self-education activities. Promote examples of } \\
\text { peer, group, parent, and family successes. }\end{array}$ & $\begin{array}{l}\text { Provide the parents with tools and resources } \\
\text { to better equip themselves for participation in } \\
\text { healthcare education, awareness, and trustworthy } \\
\text { news. }\end{array}$ \\
\hline Self-Regulation & $\begin{array}{l}\text { Controlling oneself } \\
\text { through self-monitoring, } \\
\text { goal-setting, feedback, } \\
\text { self-reward, self- } \\
\text { instruction, and } \\
\text { enlistment of social } \\
\text { support }\end{array}$ & $\begin{array}{l}\text { Parents will self-monitor own time to schedule } \\
\text { self-educational activities. Parents can set own } \\
\text { time management for self-educational activities, } \\
\text { self-monitor, and meet achievable goals. In } \\
\text { addition, instructional modules can build-in time } \\
\text { management tools, monitors, and assessment } \\
\text { systems. }\end{array}$ & $\begin{array}{l}\text { Explain how mechanisms built into the program } \\
\text { might assist parents in achieving self-awareness } \\
\text { and self-education. Instructional modules can } \\
\text { be created that are intuitive, easy-to-use, track } \\
\text { performance, track participation, track additional } \\
\text { educational needs. }\end{array}$ \\
\hline $\begin{array}{c}\text { Moral } \\
\text { Disengagement }\end{array}$ & $\begin{array}{l}\text { Ways of thinking about } \\
\text { harmful behaviors and the } \\
\text { people who are harmed } \\
\text { that make infliction of } \\
\text { suffering acceptable }\end{array}$ & $\begin{array}{l}\text { By non-engagement in self-educational activities, } \\
\text { unhealthy life choices and misinformation from } \\
\text { the wrong sources can have damaging effects } \\
\text { on the family. Misinformation about healthcare } \\
\text { is damaging and harmful to the family and also } \\
\text { encourages same negative behaviors and choices } \\
\text { made by children. The inability to self-educate can, } \\
\text { in turn, be harmful to the children. }\end{array}$ & $\begin{array}{l}\text { Assess what can assist in limiting harm of being } \\
\text { unknowledgeable, uniformed, and uneducated. } \\
\text { Promote healthcare education, awareness and } \\
\text { trustworthy news for the whole family. Explain } \\
\text { methods parents can use to educate others in their } \\
\text { sphere of influence as well. }\end{array}$ \\
\hline
\end{tabular}




\section{PRECEDE-PROCEED Implementation Model}

PRECEDE-PROCEED Implementation Model is applied in the example Social Cognitive Theory Mapping involving a group of parents [1,2]. The example is provided for parents with children of all ages who tend to take family members to allopathic doctors most often for vaccines, pharmaceutical drugs, antibiotics, and surgery. The goal of this PRECEDE-PROCEED model is to educate and inform parents and family members about:

i. preventative healthcare / self-care in the home,

ii. natural remedies found in nature,

iii. natural nonGMO, Paleolithic diet or Paleo diet, and

iv. Using naturopathy doctors, providers, and services rather than allopathic and corporate pharmaceutical services for healthcare needs.

\section{PRECEDE-PROCEED Implementation Model}

\section{A. PRECEDE has four phases:}

\section{Phase 1:}

The program's desired result is to educate parents and families about naturopathy doctors, services, providers, and healing remedies versus allopathic and Big Pharma services. The main goals of this PRECEDE-PROCEED Implementation Model are to:

a. educate and inform with specific tools, resources, curriculum, and real news / studies,

b. change health behaviors,

c. change how individuals view allopathic versus naturopathy medicine, doctors, services, and providers,

d. offer new healthcare alternatives, choices, services, and resources, and

e. Help parents and families spread newly learned knowledge to others within the target population's sphere of influence [5].

Changed negative behaviors into positive health choices are expected as well as newly gained information about how to be more proactive in healthcare education for the whole family using naturopathy services rather than allopathic, corporate pharmaceuticals.

\section{Phase 2}

The following priorities for the health behavior issue include:

a. The environmental and behavioral determinants impeding the actualization of the desired results are fake news, fake studies written by agenda-driven, big money agencies, false indoctrination, media brainwashing on television, magazines, radio, Internet, billboards (basically all media in Western nations), false medical information disseminated to the public via allopathic medical system and pharmaceutical companies b. The conditions that need to be addressed to achieve the desired results include:

i. an openness and wiliness on the part or families and parents to learn new healthcare information,

ii. time in busy lifestyles,

iii. space such as in-person and/or online assessment, curriculum modules, resources, and

iv. access to service providers willing to participate and educate in the change agenda

The environmental factors, lifestyles, and/or behaviors that influence the conditions or issues include messaging from all Western culture systems that bombard the target population with incorrect information about healthcare, healthcare choices, and the real causes of illness and disease. In addition, busy lifestyles do not help parents and families understand (or even know the importance of) how to filter out inaccurate information they are bombarded with daily and where to seek accurate healthcare information. Finally, unhealthy behaviors regarding diet and eating habits are reinforced in Western nations and the target population does not have the full awareness about their poor choices.

\section{Phase 3:}

a. Predisposing circumstances affecting environmental, attitudes, and behavioral factors having influence in Phase 2 include false indoctrination within the culture about healthcare education, healthcare / self-care, and naturopathy medical services versus allopathic, corporate pharmaceutical indoctrination.

b. Enabling circumstances affecting environmental, attitudes, and behavioral factors having influence in Phase 2 include easy access to toxic prescription pharmaceutical drugs, toxic over-the-counter drugs, vaccines, surgery, fast food restaurants, and unhealthy pre-made brand grocery store foods rather than choosing natural foods that can take more time to prepare. Other enabling factors include all Western media avenues that bombard families with false information daily.

c. Reinforcing circumstances affecting environmental, attitudes, and behavioral factors having influence in Phase 2 include everyone in the target population's lifestyle and sphere of influence are mostly likely indoctrinated with false information as well. All corporate big media avenues and the allopathic, pharmaceutical medical system serve as reinforcing agents disseminating false healthcare information and enabling dependency rather than fostering self-advocacy, self-efficacy, and the ability to self-educate or self-inform.

\section{Phase 4:}

The policy and administrative factors influencing what can be implemented include building a coalition of naturopathy doctors, clinics, services providers, and educators. In addition, building a 
database of resources, tools, services, and curriculum modules must be provided to the target population. Finally, training needs to be provided to the target population on how to use and access the tools $[5,6]$.

\section{B. PROCEED has four phases:}

I. Phase 5: The Implementation Design: Social Cognitive Theory constructs will be applied to health behaviors of the target population. The design involves "creating in-person and online workshops and instructional modules to assist parents in the development of realistic goals, decide on achievable outcomes, and tailor techniques to overcome lack of healthcare education, awareness, and barriers in accessing trustworthy news". The intervention will be conducted by addressing the healthcare needs of parents and families in a comprehensive naturopathy manner with before, during, and after medical and curriculum assessment.

II. Phase 6: The Process Evaluation: Medical and curriculum assessment will be on-going, tracked, monitored, and reported at the beginning, during, and end of the change initiative. Data will be compiled to address gaps, changes, revisions, alterations, individualized, and personalized needs of the target population. This will be done by on-going surveys, interviews, testing, and tracking of involvement in the curriculum.

III. Phase 7: The Impact Evaluation: The impact evaluation involves the monitoring and reporting aspects of

a. how well the target population learned the new information,

b. how much time was spent involved in the learning activities,

c. Whether the new information was actually applied in the daily choices, behaviors, and actions taken by the target population.

The desired impact of this intervention on the target population will be real and evident behavioral changes in the lives of parents, families, children, and individuals in their sphere of influence by way of improved health, less illness and ability to overcome illness faster, elevated self-efficacy levels, changes made in healthcare advisors and service providers (i.e. switch from allopathic to naturopathy), and changes made in diet $[5,6]$. The impact evaluative process will include direct observations, surveys, interviews, curriculum assessments, and before, during, and after medical assessments. All of the reporting and monitoring aspects listed can be done in a variety of ways such as in-person, telephone, email, online, and via curriculum module completion testing, and tracking.

IV. Phase 8: The Outcome Evaluation: The outcome evaluative process will be the same as the impact evaluation process which includes direct observations, surveys, interviews, curriculum assessments, and before, during, and after medical assessments. All of the reporting and monitoring aspects listed can be done in a variety of ways such as in-person, telephone, email, online, and via curriculum module completion testing, and tracking. Both quantitative and qualitative measures will be used throughout the program to assess, measure, track, and report findings [7].

\section{Reflection}

The most beneficial aspects of this material includes the ability to learn new ways of thinking, applying theory in one's best practices when educating others about healthcare, and interlinking theory with practical application. Practitioners, health educators, students, researchers, and community members should feel more prepared and confident choosing applicable models of evaluation as they study, practice, and apply various theoretical concepts when incorporated into their own program's evaluation needs and complexity (Frye \& Hemmer, 2012). The materials presented here can help health educators:

\section{i. Understand frameworks for building capacity,}

ii. Understand the role of health programs and policies,

iii. Understand the role of evaluation and assessment, and

iv. Apply theory-based health practices to any community health education program or agenda [8-10]. The skills and knowledge learned can be applied in both personal and professional life using theory, strategies, and intervention models to educate self, family, friends, neighbors, community, and professional associations. In addition, one can educate others in a professional capacity by understanding positive and negative influencing factors in the lives of others. Theory can be applied in personal, individualized, meaningful ways to capture the attention of others and help raise self-advocacy and selfefficacy levels for better health conditions and better health choices [11-14].

As a result of the materials presented here, one can feel confident in his or her abilities to effectively teach others how to improve health circumstances in a professional, theory-based manner. The tools presented in this paper can help health educators, practitioners, students, researchers, and community members feel more confident in having the ability to reach individuals and groups where they are at cognitively and work toward raising those abilities to higher levels of thinking, awareness, and proactive selfcare / healthcare [15-17]. Important goals to consider are to:
i. learn new ways of thinking, researching, and healing,
ii. teach others, and
iii. Pass the knowledge on within spheres of influence.

\section{Conclusion}

In closing, this healthcare educational program seeks to instruct parents and families about the choices they have in seeking out and providing naturopathy healthcare to their family and children. The program uses a Social Cognitive Theory Mapping template which maps out the overall objectives and goals of the program. In addition, the PRECEDE-PROCEED Implementation Model explains how the program will be most effective when mapped out by the expected end results anticipated by the program's goals. Finally, 
information technology will be used when interpreting educational interventions from theory into practice by mapping out the PRECEDE/PROCEED model to analyze expected outcomes of the program with quantitative and qualitative measures $[7,18,19]$.

\section{References}

1. Bandura A (2004) Health promotion by social cognitive means. Health Education \& Behavior 31(2): 143-164.

2. Sell K, Amella E, Mueller M, Andrews J, Wachs J (2016) Use of Social Cognitive Theory to assess salient clinical research in chronic disease self-management for older adults: An integrative review. Open Journal of Nursing 6: 213-228.

3. Tomlinson CA (2017) How to differentiate instruction in academically diverse classrooms. ( $3^{\text {rd }}$ edn). Alexandria, VA, USA.

4. Subban P (2006) Differentiated instruction: A research basis International Education Journal 7(7): 935-947.

5. Sharma M, Branscum P, Atri A (2014) Introduction to community and public health. San Francisco, CA, Jossey-Bass, USA.

6. Viswanath K, Rimer BK, Glanz K (2015) Health behavior: Theory, research, and practice. San Francisco, CA, Jossey-Bass, USA.

7. Weir C, McLeskey N, Brunker C, Brooks D, Supiano MA (2011) The role of information technology in translating educational interventions into practice: An analysis using the PRECEDE/PROCEED model. Journal of the American Medical Informatics Association: JAMIA 18(6): 827-834.

8. Frye AW, Hemmer PA (2012) Program evaluation models and related theories: AMEE Guide No. 67. Medical Teacher 34(5): e288-e299.

9. Mistry KB, Minkovitz CS, Riley AW, Johnson SB, Grason HA, et al. (2012) A new framework for childhood health promotion: The role of policies and programs in building capacity and foundations of early childhood health. American Journal of Public Health 102(9): 1688-1696.

10. Whitney W, Dutcher GA, Keselman A (2013) Evaluation of health information outreach: Theory, practice, and future direction. Journal of the Medical Library Association 101(2): 138-146.

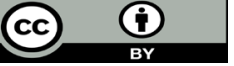

This work is licensed under Creative Commons Attribution 4.0 License

Submission Link: http://biomedres.us/submit-manuscript.php
11. Gutierrez Kapheim M, Ramsay J, Schwindt T, Hunt B, Margellos-Anast H (2015) Utilizing the community health worker model to communicate strategies for asthma self-management and self-advocacy among public housing residents. Journal of Communication in Healthcare 8(2): 95105.

12. Hagan T, Rosenzweig M, Zorn K, van Londen G, Donovan H (2017) Perspectives on self-advocacy: Comparing perceived uses, benefits, and drawbacks among survivors and providers. Oncology Nursing Forum 44(1): 52-59.

13. Kamimura A, Nourian MM, Jess A, Chernenko A, Assasnik N, et al. (2016) Perceived benefits and barriers and self-efficacy affecting the attendance of health education programs among uninsured primary care patients. Evaluation and Program Planning 59: 55-61.

14. Stage CV, Roseno A, Hodges CD, Hovland J, Diaz S, et al. (2016) Implementation of a food-based science curriculum improves fourthgrade educators' self-efficacy for teaching nutrition. American Journal of Health Education 47(3): 155-162.

15. Dean E, Greig A, Murphy S, Roots R, Nembhard N, et al. (2016) Raising the priority of lifestyle-related noncommunicable diseases in physical therapy curricula. Physical Therapy 96(7): 940-948.

16. Field TA, Beeson ET, Jones LK (2016) Neuroscience-informed cognitivebehavior therapy in clinical practice: A preliminary study. Journal of Mental Health Counseling (2): 139.

17. Giordano G (2009) Solving education's problems effectively: A guide to using the case method. Lanham, MD, USA: R\&L Education.

18. TchouaketE, Broussell A(2013) Using the results of economic evaluations of public health interventions: Challenges and proposals. Journal of Program Evaluation 28(1): 43-66.

19. Thalacker KM (2011) Hypertension and the Hmong community: using the health belief model for health promotion. Sage Journals: Health Promotion Practice 12(4): 538-543.

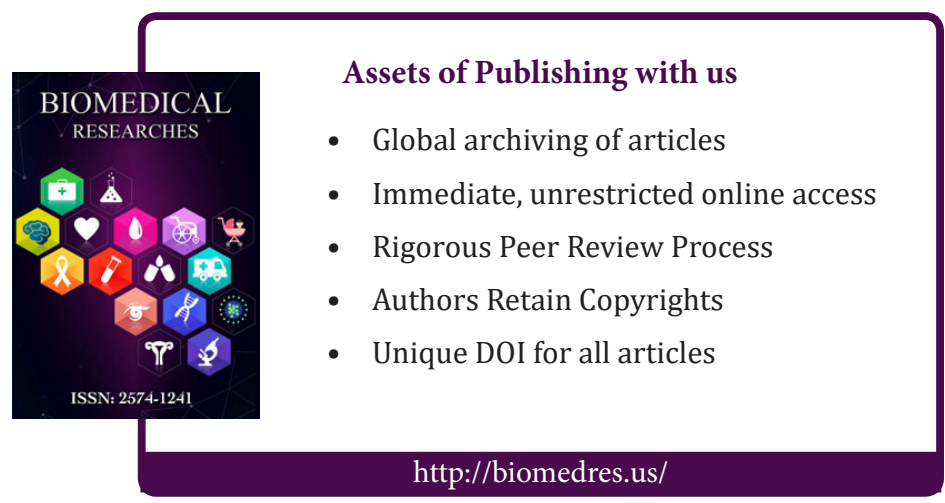

